\title{
La crisis europea en Revista de Occidente (1923-1936) *
}

\author{
Juan Pablo Camazón Linacero
}

\begin{abstract}
RESUMEN ABSTRACT
\end{abstract}
En este articulo, el autor analiza la In this article, the author analyses crisis europea y la depresión económica en el periodo de entreguerras, prestando atención principalmente a las repercusiones de estos hechos en la obra de José Ortega y Gasset y en Revista de Occidente. La crisis de conciencia y la idea de Europa, el papel de las elites y el acceso de las masas al poder social son las cuestiones fundamentales tratadas por los escritores de Revista de Occidente. También explica las soluciones económicas que propuso la revista.

\section{PALABRAS CLAVE}

Europa, decadencia, crisis, Crack del 29, Depresión económica, elites, masas. the European crisis and the economic Depression in the inter-war period, paying attention principally to the repercussions of these events in the work of José Ortega y Gasset and in Revista de Occidente. The crisisconsciounsness and the idea of Europa, the role of the élites and the accession of the masses to the social power are the fundamental questions treated by the writers of Revista de Occidente. Also, he explains the economic solutions that the review proposes.

\section{KEY WORDS}

Europa, decadence, crisis, Crack of 29, economic Depression, élites, masses.

* (Las obras completas de José Ortega y Gasset se citan en número romano, correspondiente al tomo, y a continuación las páginas. RO es Revista de Occidente.) 


\section{INTRODUCCIÓN}

inmerso en el ambiente pesimista de la primera postguerra mundial, en julio de 1923 José Ortega y Gasset funda la Revista de Occidente y la dirige hasta julio de 1936, en que el estallido de la Guerra Civil Española impone su cierre. La importancia y calidad de la publicación en el ámbito cultural han sido ampliamente reconocidas ${ }^{~}$. La revista sirvió a sus lectores puntualmente, en sus 157 números mensuales, las noticias, los artículos y la información bibliográfica más relevante de intelectuales y escritores de dentro y fuera de España.

Una nómina de sus colaboradores, tan sólo a modo de ejemplo, obliga a hacer mención al físico alemán Albert Einstein, a los economistas Werner Sombart o Lliwdin von Misses, a los filósofos Max Scheller, Xavier Zubiri, José Gaos, al poeta chileno Pablo Neruda, al escritor argentino Jorge Luis Borges, a muchos de los integrantes de la generación del 98 como Azorín o Baroja; y, en fin, a toda la del 27 con Alberti, Lorca, Gerardo Diego, Miguel Hernández y un largo etcétera.

De manera que, con tal plantilla de colaboradores, pocos temas dejaron de ser tratados en la nueva publicación: desde la teoría de la relatividad, que ponía en cuestión la legalidad de la física moderna, a los novedosos planteamientos filosóficos como la fenomenología, pasando por los nuevos cauces de expresión estética, sobre todo, en literatura.

Una de las cuestiones que más preocupaba en los ambientes políticos $e$ intelectuales de aquella postguerra fue lo que vino a denominarse "crisis de la conciencia europea" y que no era sino una reflexión sobre la pérdida del protagonismo de Europa en el mundo. Los primeros sintomas escritos aparecieron en textos redactados en el transcurso de la Gran Guerra Europea. Sin duda, la aparición antes de terminar el conflicto de la primera entrega de la Decadencia de Occidente, de Oswald Spengler, constituyó el acontecimiento más espectacular en este sentido. Durante la década de los veinte, Europa conocerá una formidable producción que daba continuidad a la cuestión de la depresión moral y política del viejo continente.

No pasó desapercibida la Decadencia de Occidente para el público español. En 1923 la Biblioteca de ideas del siglo xx, a la sazón dirigida por Ortega, editó la obra vertida al castellano por Manuel Garcia Morente. EI mismo Ortega se encargó de suscribir un prólogo en el que daba cuenta del

Lopez-Campillo, Evelyne, "La Revista de Occidente" y la formación de minorias, 1923 1936. Madrid, Taurus Ediciones, 1972. 
éxito alcanzado en una Alemania derrotada que "sentía una transitoria depresión que el título del libro venía acariciar, dándole una especie de consagración ideológica». Pero a renglón seguido afirmaba que, salvando la coyuntura bélica, "es un libro que nace de profundas necesidades intelectuales y formula pensamientos que latían en el seno de nuestra época"?

¿Hasta qué punto era cierta la aseveración de que el tema de la decadencia flotaba en el ambiente de la época y que ya había sido formulado por otros? Desde luego la cuestión no era ajena en absoluto a la propia trayectoria del pensamiento orteguiano.

\section{ORTEGA Y GASSET, «EL DECADENTE»}

Las ideas de crisis, decadencia y desastre eran moneda de cambio en la llamada Generación del 98. Sin duda, la reflexión llevada a cabo por Ernest Renan a propósito de la derrota de su país en la Guerra franco-prusiana prestó un asidero a aquella generación ${ }^{3}$. Pero el impacto de la histórica pérdida de las últimas colonias ultramarinas hubo de resultar aún más determinante.

Semejantes ideas estarán presentes en la primera empresa de carácter político impulsada por Ortega. En 1913 funda la Liga de Educación Política. En el Prospecto ${ }^{4}$, amén de su propuesta de la acción nacionalizadora de una minoría intelectual sobre las masas, proclama la ruptura intergeneracional con el recuerdo del Desastre:

"No se debe olvidar que formamos parte de una generación iniciada en la vida a la hora del desastre postrero, cuando los últimos valores morales se quebraron en el aire, hiriéndonos con su caída. Nuestra mocedad se ha deslizado en un ambiente ruinoso y sórdido" ${ }^{5}$.

Una idea vinculada al tema de la decadencia será la disección entre una España oficial, "que se obstina en prolongar los gestos de una edad fenecida", y otra "tal vez no muy fuerte, pero vital, sincera, horada, la cual, estorbada por la otra, no acierta a entrar de lleno en la historia", distinción

\footnotetext{
2 Ortega y Gasset, José, Obras Completas. Madrid, Alianza, 1983. VI, 309. 12 vols. VI, págs. 309.

Cacho VIu, Vicente, Los intelectuales y la política. Perfil público de Ortega y Gasset. Madrid, Biblioteca Nueva. 2000. págs. 77-85 y 101-118.

4 , 300-307.

5 I, 303.
} 
que Ortega tratará expresamente en la conferencia Vieja y nueva política ${ }^{6}$ pronunciada en el teatro de la Comedia en Madrid, en marzo de 1914.

La Primera Guerra Mundial no estará exenta en Ortega de esta reflexión sobre la decadencia y el mito modernista de la muerte y resurrección. De forma recurrente, el pensador insistirá en que la guerra arrumbará todo un orden viejo, vendrá otro nuevo, al que vincula la regeneración de un país neutral al conflicto. Así cuando se funda y dirige el semanario España, en el primer artículo de presentación, "España" saluda al lector y dice ${ }^{7}$, publicado en enero de 1915, afirma: «De la guerra saldrá otra Europa. $Y$ es forzoso intentar que salga también otra España" ${ }^{8}$.

En 1916 aparece el tomo I de El Espectador, con la clara intención de alejarse de la actividad pública precedente. Uno de los primeros ensayos lleva el título de Horizontes Incendiados ${ }^{9}$, en el que Ortega manifiesta la profunda amargura que le produce la guerra y que ésta "hace temblar en sus cimientos todas las aparentes inconmovilidades".

Próxima la conclusión de la Gran Guerra Europea, en otoño de 1918, Ortega escribe en El Sol una serie de artículos en los que vuelve a incidir sobre la cuestión del cambio operado por el conflicto: La Paz y España ${ }^{10}$, En el momento de la paz ${ }^{11}$, Los momentos supremos ${ }^{12}$. Según el pensador, asistimcs a «la liquidación de todo un pasado» que afectan al sistema de convicciones jurídicas y morales que, rebasadas por la propia realidad, devienen caducas.

En Meditaciones del Quijote (1914) incluyó la "circunstancia» española como una de las fundamentales que rodean al "yo" personal, no sin cierto desgarro existencial. Ortega no abandonó la preocupación por la identidad nacional, al contrario, la madura y culmına con España Invertebrada (1921).

El ensayo, criticado por su falta de base histórica, se entiende mejor dentro del contexto de la crisis española que desde 1917 Ortega vivió al día participando activamente como columnista en El Sol; de hecho, Espa. ña Invertebrada verá la luz a modo de folletones en el gran diario madrileño. La sensación de caos nacional, de desorganización y ausencia de poder que trasladan al pensador sucesos como las Juntas de Defensa, la

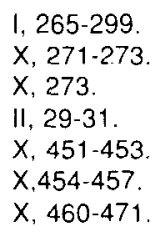


huelga general, la represión, los sucesivos gobiernos de concentración nacional, la asamblea de parlamentarios en Barcelona, los nacionalismos emergentes, hacen posible la intelección de su teoría sobre los particularismos, ya sean políticos o sociales, ya territoriales, pero dañinos todos ellos por igual al proceso incorporativo en que una nación consiste. Ortega localiza la invertebración de España en la ausencia de los mejores. La decadencia española, a juicio del pensador, no respondía a la realidad histórica; más bien, el país nunca tuvo de donde descender.

En indudable clave elitista y en perfecta armonía con lo expresado en España Invertebrada, escribirá Imperativo de intelectualidad ${ }^{13}$, publicado en El Sol en enero de 1922. Ortega iniciará el artículo con un leve recordatorio de la crisis española: “...todo va en grave derrota». Empero, tal pesimismo se tornará en un no menos radical optimismo cuando Ortega encuentra en la favorable situación de la cultura española la única salida a la crisis. Y, además, la única proyección de España en el mundo con visos de éxito. A juicio de Ortega, en la clase intelectual reside la única posibilidad de constituir una minoría selecta "capaz de influir hondamente en los destinos étnicos y dar un comienzo de nueva organización a este pueblo nuestro que se deshace y atomiza día por día”.

A continuación hace un análisis de las relaciones entre inteligencia y política. Recordará la "sazón guerrera" en la que tantos intelectuales se pusieron desafortunadamente al servicio de las pasiones bélicas. Y constata una crisis europea:

"La depresión científica y literaria que hoy padecen esas naciones próceres se debe, más que a pretexios económicos, a haber sido cegadas las fuentes de creación espiritual por haber querido mover con ellas las muelas de los molinos políticos» ${ }^{14}$.

España Invertebrada cosechó un éxito rotundo. La segunda edición sale en octubre de 1922. En el Prólogo ${ }^{15}$, el autor reflexiona sobre su propia obra; lo más destacable es la insistencia en una crisis generalizada en todo el continente:

"Al analizar el estado de disolución a que ha venido la sociedad española, encontramos algunos síntomas e ingredientes que no son exclusivos de nuestro pais, sino tendencias generales hoy en todas las naciones europeas" ${ }^{16}$.

\footnotetext{
$13 \mathrm{XI}, 11-13$.

$14 \times 1,12$.

15 III, $37-41$

i6 III, 39.
} 
La gran crisis europea no tiene su causa en la conflagración mundial. Temporalmente, además, la precede. Para Ortega «Europa padece una extenuación en su facultad de desear, que no es posible atribuir a la guerra". Aunque por el momento no entrará a analizar una crisis que efectivamente pendía de forma generalizada sobre la intelectualidad, el pensador extraerá una conclusión muy importante, a saber, "que a los males españoles descritos por mi no cabe hallar medicina en los grandes pueblos actuales. No sirven de modelos para una renovación porque ellos mismos se sienten anticuados y sin un futuro incitante".

Por lo tanto, a la altura de 1923, ciertamente Ortega y Gasset se encontraba en condiciones de afrontar una reflexión sobre la tan traída y llevada decadencia, asunto que, por lo visto, había recogido de la Generación del 98, trasladó a la del 14 y decidió incorporar a la Revista de Occidente.

\section{COSMO... INTELECTUALISMO Y OCCIDENTALIDAD}

No resulta, en absoluto, difícil el precisar cuáles fueron los motivos que indujeron a Ortega a fundar la Revista de Occidente. La nueva publicación abría sus páginas con Propósitos ${ }^{17}$, artículo de presentación en el que su director expresaba la existencia en España e Hispano-América de un público deseoso de ideas. Ortega añadía que la revista procuraría noticiar el panorama esencial de la vida europea y americana. Occidentalidad y cosmopolitismo serían sus rasgos más sobresalientes. Aunque no fijaba con precisión lo quería expresar con ambos términos, sí adelantó una leve alusión a que la «postguerra, bajo adversas apariencias, ha aproximado a los pueblos»y que frente al "internacionalismo verbal y de gesto" de antes, ahora se imponía un cosmopolitismo que significa "reconocimiento y confrontación» de los genios y destinos étnicos 0 , en otros términos, de las naciones.

Sobre el tema del cosmopolitismo insistió en un artículo publicado en la revista y que hubo de interesar mucho en los círculos intelectuales a juzgar por su aparición casi simultánea en la alemana Die Neue Rundschau. En dicho artículo, bajo el título Parerga-Cosmopolitismo ${ }^{18}$, de diciembre de 1924, Ortega se mostró más claro sobre la cuestión. El filósofo se ocupó de certificar el fracaso del internacionalismo político representado por la Sociedad de Naciones, en cuyo primer lustro de existencia se mostró incapaz de asumir el papel asignado por el Tratado de Versalles.

$17 \mathrm{VI}, 313-314$.

18 IV, $485-491$. 
La idea no admitía discusión: existía en Europa y América un grupo de intelectuales en convivencia espiritual por encima de las masas y que trascendía las fronteras nacionales. Era el ecumenismo de la inteligencia, compuesto por un grupo de espíritus selectos con una misión que determinó en Reforma de la inteligencia ${ }^{19}$, de enero de 1926: forjar las nuevas normas, los principios superiores, cuya ausencia había causado precisamente la grave crisis de Occidente.

Ortega trasladó a la Revista de Occidente la explicación clásica de la decadencia que encontró en la historia de Roma el modelo apropiado. Durante la segunda década del siglo, en muchos de sus trabajos menciona a Otto Seek y su Decadencia del mundo antiguo ${ }^{20}$, cuyas conclusiones sobre la penalización de los mejores sirve a Ortega de base para sostener su teoría elitista.

El recurso a la Historia de Roma de Monnsen, con el que precisamente abre las primeras páginas de España Invertebrada, se convierte en cita obligada del pensador para comprender la formación in crescendo de las naciones occidentales, anverso de lo que será su descenso histórico. En mayo de 1926 la Revista publica un estudio de Max Weber, Causas sociales de la decadencia del mundo antiguo. Ortega comentará este ensayo en Sobre la muerte de Roma fechado en 1926 y publicado en el tomo VI de El Espectador, de 1927, al mismo tiempo que el historiador ruso Rostovtzeff publica la Historia económica y social del Imperio romano, obra a la que Ortega también aludirá en numerosas ocasiones para apoyar sus tesis elitistas.

El estudio de Max Weber, escrito con anterioridad al de Spengler, se centra en las causas económicas de la caída del Imperio romano. Pero Max Weber, a quien Ortega reconoce como maestro al remitir la explicación histórica a una multitud de causas, no explica por qué, sino cómo muere Roma. Ortega cree que las causas externas no son decisivas; la cuestión radica en las causas endógenas: la amenaza exterior de los bárbaros no provoca la caída del Imperio, sino que se trata de un desplome provocado por causas internas. Entre las causas profundas de carácter político, a las que dedica la segunda parte del ensayo, Ortega descubre el colapso del proceso histórico en la disociación entre Roma y la provincia.

\footnotetext{
IV, 493-500.

$20 X, 264$. En otras ocasiones Ortega cita de forma diferente al autor y a su obra: Otto Seeck, Decadencia del mundo antiguo $X, 660$.
} 


\section{PESIMISMO EN LOS HAPPY TWENTY}

Así las cosas, la tendencia de la Revista de Occidente a tratar el tema de la decadencia de Europa pronto quedó patente desde los primeros números. En el de agosto de 1923, Manuel García Morente publica Una nueva filosofía de la historia. ¿Europa en Decadencia? ${ }^{21}$ en el que se da cuenta de La decadencia de Occidente. García Morente expone y sintetiza la obra de Spengler: no hay historia universal en el sentido de la historia de la humanidad, sino de las culturas, concebidas como organismos vivos. La civilización es el último estadio de la cultura «en el que se han agotado todas las posibilidades creadoras". A ese punto ha llegado la civilización occidental.

A esta idea de la decadencia se asociaría inmediatamente la cuestión relativa a su unidad. El profesor de la Universidad de Colonia, Guillermo Haas, escribe Los tipos de humanidad: La unidad de Europa ${ }^{22}$, en diciembre de 1924. La tesis de Haas es la siguiente: «la estructura y cultura del europeo es la unidad en la multiplicidad"; y en una diferenciación entre Oriente y Occidente, idea común a los colaboradores de la revista, opondrá que la característica de Asia es el principio plural. La estructura e historia de Europa revela la creación de una gran cultura común, técnico-científica, en la que participan todos sus miembros, aunque no en igual medida.

El principio de unidad en la multiplicidad, según Haas, se ha manifestado en cuatro grandes creaciones europeas: el hombre griego (unidad de lo biológico y lo espiritual: cuerpo y alma); el derecho romano (administración y regulación del imperio y sus partes); la teología cristiana (el dogma de la Trinidad: un solo Dios en tres personas distintas); y en la ciencia y la técnica (construcción intelectual de la naturaleza: experimento y ley general).

Avalado por La crise de /'Esprit (1919), Paul Valéry se mostrará menos sistemático que Haas en Notas sobre la grandeza y la decadencia de Europa ${ }^{23}$, publicado en abril de 1927 . El intelectual francés efectúa un balance político circunscrito al mundo de postguerra en el que "Europa espira a ser gobernada por una comisión americana». Europa se ha distinguido no por su política sino por su libertad de espíritu, por su voluntad de disciplina, por una curiosidad certera y activa $y$, concluye Valéry,

\footnotetext{
21 Garcia Morente, Manuel, "Una nueva tilosofía de la historia. ¿Europa en decadencia?", RO, n. ${ }^{\circ}$ 2: agosto 1923, págs. 173-182.

22 HAAS, Guillermo, "Los tipos de humanidad: La unidad de Europa", RO. n. 18, diciembre 1924, págs. 353-396.

VALÉFY. Paul. "Notas sobre la grandeza y la decadencia de Europa", RO, n."46, abril 1927, págs. 1-14.
} 
por un capital de leyes y procedimientos muy poderosos. Valéry constata que Europa se encuentra en un estado de "guerra suspendida" y que no hay paz verdadera. La política de nación a nación ha fracasado y Europa junto al resto de continentes se encuentran en un proceso generalizado en el que "nada se hará donde no se mezcle el mundo entero".

Dos obras póstumas de Kafka, El Proceso y El Castillo, son comentadas por R. M. Tenreiro en una Nota ${ }^{24}$ publicada en junio de 1927. Ambas obras, a juicio del comentarista, describen un ambiente en crisis, irracional y onírico: una causa criminal inmotivada desarrolla El Proceso en la «vil promiscuidad de uno de esos inmensos caserones urbanos en que se amontona, lamentablemente, el proletariado en cualquiera de las grandes capitales del Norte"; y una aldea alemana, en donde se sitúa El Castillo. El tribunal y el misterioso castillo gobiernan los destinos del ser humano abandonado a su suerte en un mundo adverso.

La posición de los intelectuales preocupaba a Ortega y no pasó desapercibida para la revista una de las obras con más fuerza explicativa de aquella conciencia en crisis; se ocupó de ella Luis de Zulueta en una Nota publicada en marzo de 1928, con el título Julien Benda: La trahisión des clercs (Paris, Grasset. 1927) ${ }^{25}$. Zulueta da cuenta de que la traición de los clérigos, de los intelectuales, estribaba en haber abandonado la defensa del espíritu para pasarse al campo de lo temporal, transformado la inteligencia en utilitaria y provocando una sociedad materialista. Zulueta opondrá que no siempre es traidor el intelectual que se afilia a verdades particulares.

La revista se ocupó de Europa desde otras perspectivas, no exclusivamente políticas, que versaban sobre aspectos culturales y sociales. En este apartado estaría Europa destruida ${ }^{26}$, suscrito por Waldo Frank, uno de los colaboradores norteamericanos más asiducs; Europa destruida formó parte del libro Redescubrimiento de América y, según adelantaba el número de junio de 1929, se publicaría ese mismo mes en la Biblioteca de la Revista. Frank realizará un largo estudio de la historia europea para concluir que el maquinismo moderno esclaviza al hombre europeo, cuando paradójicamente, la máquina había sido el logro de la ciencia y de la técnica para dominar la naturaleza: en el fondo, el hombre se ha desprendido de su espiritualidad. La cultura afectada por la técnica será objeto de estudio en El proceso de

24 Tenreiro, R.M., "Franz Kafka.- Der Prozess. Verlag Die Schmiede.- Berlín, 1925.- Das Schloss. Kurt Wolff Verlag.- München, 1926", RO, n. "48, junio de 1927, págs. 385-389.

25 Zuzueta (de), Luis, "Julien Benda: La trahision des clercs", RO, n. 58, marzo 1928, págs 417-421.

26 Frank, Waldo, «Europa destruida», RO, n. 72, junio 1929, págs. 354-379 
neutralización de la cultura ${ }^{27}$, publicado en febrero de 1930, y que recogía el texto de una conferencia dada en Barcelona por Carl Schmitt.

Un análisis de la situación social de la mujer en Europa, llevado a cabo por el psiquiatra austríaco Carl Gustav Jung, colaborador de Freud en el inicio de su carrera, incide en los cambios sociales operados en Europa. En octubre de 1929 aparece La mujer en Europa ${ }^{28}$; Jung afirma que el mundo de la mujer está indisolublemente unido al del hombre; a partir de aquí analiza cuestiones relativas a la independencia social de la mujer, el papel del inconsciente en la mente femenina y la formación de la neurosis, la tradicional institución del matrimonio que el hombre teme perder y del que la mujer duda, las medidas "anticoncepcionales", "la relación anímica entre sexos", el eros y el logos de las relaciones sexuales. Yung concluye que «la mujer del presente tiene delante de sí una formidable tarea cultural, que tal vez significa el nacimiento de una nueva época".

\section{INTELIGENCIA VERSUS TOTALITARISMO}

La Revolución Bolchevique (1917) y la Marcha sobre Roma (1922) inauguran en Europa la instauración de los regímenes totalitarios, que determinaron, entre otras causas, la radicalización del periodo de entreguerras. La revista mostrará un gran interés por Rusia y, en menor medida, por Italia, los dos países representativos de las nuevas experiencias políticas que hacian tambalear el Estado liberal de Derecho. La posición de los intelectuales ante comunismo y fascismo importó bastante a la Revista de Occidente, que promovería la publicación de artículos al respecto.

Una Nota ${ }^{29}$ de Luis de Zulueta, publicada en febrero de 1925, comenta el libro Lénine et le payssan russe, de Maximo Gorki. Plantea Zulueta las relaciones entre la minoría revolucionaria de intelectuales y los "ciento cincuenta millones de campesinos" hostiles a toda civilización. Zulueta resalta la idea leninista de que no hay intelectuales iridependientes.

La revista, de espíritu cosmopolita, insistira principalmente en las impresiones recibidas por la intelectualidad europea en los viajes a Rusia. $139-221$

27 SchmITt, Carl, «El proceso de neutralización de la cultura», $R O, \mathrm{n} . “ 80$, febrero 1930 , págs.

28 Jung, Carl G., "La mujer en Europa», RO, n."76, octubre 1929, págs. 1-32.

29 ZuluetA, Luis de, "Maxime Gorki: Lénine et le paysan russe. Ed. Sagittaire, París, 1925.", RO, n. 20, febrero 1925 , págs. 249-254. 
Así Manuel García Morente explica en una Nota ${ }^{30}$ el artículo que el historiador alemán Eduard Meyer escribió para la Deutsche Rudschau. El panorama de la revolución soviética descrito por Meyer resulta positivo, salvo el juicio que emite sobre la labor científica: aunque la actividad de las ciencias aplicadas, con fines prácticos, se ha incrementado, la ortodoxia marxista ha ahogado el desarrollo de la actividad intelectual más teórica, como la filosofía o la historia.

Antonio Espina comenta en una Nota ${ }^{31}$ varios libros sobre Rusia, no sin antes afirmar que el pueblo ruso tiene una "tara espiritual» que es la tara asiática, un pueblo fatalista, místico y aislado. A continuación relaciona $A$ Short view of Russia, del economista inglés John Maynard Keynes; Mi viaje a la Rusia soviética, del socialista español Fernando de los Ríos; Ce que j'ai vu à Moscu, de Henri Béraud que muestra su desilusión por la experiencia comunista que, a su juicio, no deja de ser un "fascismo israelita"; Voyage sentimental, de Chklovsky, de carácter biográfico, en el que trasluce la desesperanza de ser humano después de la utopía; y, por último, La nueva Rusia, de Julio Álvarez del Vayo, libro que ensalza Antonio Espina y en el que se repasa de forma completa la vida rusa desde la Revolución, haciendo hincapié sobre la propaganda del comunismo entre los pueblos oprimidos de Oriente.

La revista dará a conocer el momento literario y filosófico. A ello responden dos artículos: uno de Wladimir Astrow, Por una nueva literatura rusa ${ }^{32}$, de abril de 1926; el otro de Iván Luppol, La filosofía en la Rusia soviética ${ }^{33}$, de septiembre de 1927. En ambos se relatan los acontecimientos concernientes a la situación de los intelectuales dentro de la Revolución: la lucha entre los literatos "concurrentes", no afines al comunismo, y los proletarios, de una parte, y entre filosofía materialista y libre, de otra.

La otra gran novedad política del periodo de entreguerras fue el fascismo. Una primera toma de contacto de los lectores con la Italia fascista se produce con la publicación en mayo de 1925 de una Nota de E. Diez-Canedo, Nueva visita a d'Annunzio ${ }^{34}$. Se trata de una nota laudatoria de la figura del poeta italiano Gabriel d'Anunzio, considerado, por entonces, una de las leyendas en vida inspiradora del Fascismo. A ello había contribuido

\footnotetext{
30 Garcia Morente, Manuel, "La nueva Rusia», RO, n. 35, abril 1926, págs. 393-401

31 ESPINA, Antonio, "Varios libros acerca de la nueva Rusia de Álvarez del Vayo, Béraud Chklosvski», RO, n. 36, junio 1926, págs. 372-380.

32 Astrow, Wladimir, "Por una nueva literatura rusa", RO, n. 34, abril 1926, págs. 85-98

33 LupPol, Iván, “La filosofía en la Rusia soviética», RO, $n .{ }^{\circ}$ 51, septiembre 1927, págs. 357-370.

34 E. Diez-CANedo, "Nueva visita a d'Annunzio. ", R. de O., mayo de 1925, n. 23, págs. 251-255.
} 
la toma y ocupación del Fiume en septiembre de 1919 por d'Annunzio con sus legionarios. Diez- Canedo presenta en su Nota a un d'Annunzio que reúnen la doble condición de hombre de letras y de armas.

No se repitieron, en absoluto, este tipo de panegíricos en la Revista. Tal vez la evolución histórica del fascismo hacia una dictadura descarnada, justamente partir de 1925, justifica el cambio. Así las cosas, la revista informa sobre dos libros publicados por otras tantas figuras del fascismo. El primero de Alfredo Rocco, Ministro de Justicia de Mussolini, encargado de trazar la arquitectura jurídica del nuevo Estado. El segundo de Curzio Malaparte, uno de los intelectuales fascistas más destacados. En el tono empleado para presentar los libros y criticarlos se advierte un giro copernicano con relación a la Nota de d’Annunzio.

Serna y Favre, colaborador habitual de la Revista en temas constitucionales y jurídicos, suscribe en Octubre de 1927 la Nota sobre La Transformazione dello Stato (1927), de Alfredo Rocco ${ }^{35}$. La sensibilidad jurídica de Serna Favre se siente herida por la nueva articulación jurídica-pública del estado fascista, precisamente en Italia, cuna del Derecho. Desde la Marcha sobre Roma hasta 1925, el Fascismo no era otra cosa que pura acción; con la obra legislativa de Rocco, se procede a la desarticulación legal del Estado liberal procedente del Risorgimento y se fragua la base del nuevo Estado. En la obra normativa de Rocco destacan tres leyes que suponen la gran transformación del Estado italiano: la Ley sobre la facultad del Poder ejecutivo de emanar normas jurídicas, la Ley sobre las atribuciones y prerrogativas del Jefe del Gobierno y la Ley sobre la regulación jurídica de las relaciones colectivas del trabajo, ésta última considerada por Rocco como «la transformación más profunda que el Estado nunca haya sufrido desde la Revolución francesa en adelante".

La actitud de uno de los intelectuales fascistas más significados será objeto de una dura crítica por parte de Ángel Sánchez Rivero, a propósito de un libro de Curzio Malaparte titulado I'Italie contra l'Europe. La Nota se publica en el número de abril de 1928. Malaparte es presentado como el auténtico escritor fascista, que ha vivido la experiencia de la guerra y la decepción posterior. En esto se diferencia de otros escritores como Marinetti, Pirandello y D'Anunnzio. Nos encontrariamos con el intelectual desnaturalizado por la sujeción al poder político, justamente la línea contraria marcada por la revista. Sánchez Rivero critica en su Nota la interpretación

35 Serna y Favre, “J. G. Alfredo Rocco: La Transfoimazione dello Stato. 1927.» R. de O., n. 52, octubre 1927, páys. 121-129. 
del movimiento fascista como una reacción de Italia contra Europa. La crisis de la unidad de Europa es una crisis de la conciencia europea y, dentro de ella, de Italia, pero nunca como fenómeno exclusivamente suyo. Al tenor de la obra de Malaparte, el fascismo para Sánchez Rivero más bien sería calificable como un movimiento de Italia contra Italia.

\section{LAS MASAS AL PODER}

Al regreso de su segundo viaje a Argentina, Ortega y Gasset comienza a publicar una serie de folletones en el diario El Sol, entre el 24 de octubre de 1929 y el 19 de agosto de 1930, coincidiendo justamente con la actividad de la Revista preocupada en extremo por la depresión espiritual de Europa. El primero de estos artículos no es sino reflejo de la conferencia, El Hecho de las aglomeraciones, pronunciada en Buenos Aires. En definitiva, se trata de una profunda reflexión sobre la sociedad contemporánea que el 31 de agosto de 1930 edita como libro con un provocador título: La rebelión de las masas ${ }^{36}$.

El ensayo, probablemente la obra más conocida de Ortega, es un análisis de la sociedad de masas sobre la base de una antropología negativa referida al hombre medio. El estudio de la sociedad europea, caracterizada por la rebelión del hombre-masa, constituye la primera parte del libro. En ella se atiende a las causas internas de la decadencia de Europa: las masas incumplen el postulado orteguiano de que la sociedad es una relación dinámica entre mayorías vulgares y minorías egregias.

La segunda parte de la Rebelión de las masas responde a una cuestión, Quién manda en el mundo que, por lo demás, sirve de título. Ortega formula toda una teoría sobre la sociedad internacional y el poder mundial para, posteriormente, defender la unidad de Europa mediante la superación de los Estados nacionales. Se ocupó en esta segunda parte también de la decadencia de Europa en su aspecto externo, es decir, comparándola con las potencias emergentes: Rusia y Estados Unidos.

La Rebelión de las masas obtuvo un notable éxito, incluso, entre el gran público que, por paradójico que resulte, no salía muy bien parado en el ensayo. Por supuesto, la elite de colaboradores de la Revista de Occidente lo celebró con mayor fundamento a juzgar porque las tesis mantenidas por

36 ORtega y Gasset, La rebelión de las masas, Edición de Thomas Mermall. Madrid, Editorial Castalia, 1998., págs. 30. 
Ortega fueron, a parir de entonces, asimiladas como auténticos axiomas determinantes de su línea editorial.

\section{LA GRAN DEPRESIÓN}

Desde la Revista de Occidente Ortega promovió una extensa publicación de artículos encaminados a resaltar aspectos negativos de la sociedad norteamericana. Racismo, desmitificación de la mujer americana, capitalismo tardío sin base social y ausencia de producción intelectual que contrastaba con la properity, presentada como el producto de la técnica y del choque con un continente nuevo y virgen, exuberante de riquezas.

Ya en 1924 la Revista de Occidente se hizo eco del pensamiento americano heterodoxo de Waldo Frank, dando noticia de sus obras Salvos y Our América ${ }^{37}$. Frank resaltaba que "más ricos que nunca en seguridades físicas, padecemos indigencia en bienes espirituales». Continuó la revista tratando temas relativos a la sociedad americana, con cierta carga peyorativa, como en La "Cristian Sciencie" en América ${ }^{38}$, de Moritz Geiger, o un largo ensayo titulado El Ku Klux Klan ${ }^{39}$, de Frank Bohn. En La mujer norteamericana ${ }^{40}$ el mismo Frank se ocuparía de los mitos femeninos. La «invasión del norteamericanismo" servía de presentación al ensayo de Teodoro Lüddecke significativamente titılado El americanismo realidad y tópico ${ }^{41}$.

Esta tendencia de la Revista enlazaba perfectamente con la convicción orteguiana en una América joven, inexperta, sin principios morales e incapaz de asumir el liderazgo mundial, tal y como sostuvo en Hegel y América ${ }^{42}$, un pequeño ensayo publicado en el tomo VII de El Espectador, y en la Rebelión de las masas, ambos publicados en 1930. Tales ideas encontraron en la depresión económica, subsiguiente al desplome de la bolsa de Nueva York, su sanción histórica irrefutable.

En Los «nuevos" Estados Unidos ${ }^{43}$, publicado en La Nación de Buenos Aires, en marzo de 1931, y Sobre los Estados Unidos ${ }^{44}$, aparecido en

\footnotetext{
Sanchez Rivero, A. "Waldo Frank: Salvos", R. de O., n. 11, mayo de 1924, págs. 248-255. Gieger, Moritz, "La "Christian Sciencie" en América", RO, n. ${ }^{\circ} 19$, enero 1925, págs. 58-99. BoHn, Frank, “El Ku Klux Klan", RO, n. ${ }^{\circ} 42$, diciembre 1926, págs. 324-358.

"Frank, Waldo, "La mujer norteamericana", R. de O., n." 58, enero 1929, págs. 72-82

LUDDECKE, Teodoro, “El americanismo, realidad y tópico", $R O, n .{ }^{*} 72$. marzo 1930, págs.

$42 \quad$ II, 563-576.

43 IV. 357-361.

44 IV, 369-375.
} 377-396. 
Luz, en julio de 1932, recordó a los lectores el acierto de su diagnóstico. La depresión vital de Europa, en otras palabras su decadencia, tenía su causa, entre otras, en la falsa idea sobre los Estados Unidos. El viejo continente quedó deslumbrado por la prosperity americana. El error de los europeos radicaba en no apreciar que los Estados Unidos viven una «existencia colonial», subsiguiente a la colonización, con dos características: que se trata de una vida transitoria y no autóctona. El hombre colonial retrocede hacia un relativo primitivismo: exuberancia de medios, por un lado, y simplicidad de problemas, por otro. En este sentido Ortega considera primitiva y prepotente a Norteamérica.

En 1931 la Revista publica dos estudios sobre la economía americana. En el primero de ellos titulado El capitalismo norteamericano ${ }^{45}$, del libro El Estado y la Sociedad en Norteamérica, Charlotte Lütkens, sostiene que el americano es un pseudo-capitalismo y su liberalismo encubren un subdesarrollo social interno. En el segundo, M. J. Bonn suscribe El sentido de la crisis norteamericana ${ }^{46}$ y su tesis fundamental es que la importancia de la crisis radica en el hecho de que Estados Unidos se ha despojado de su carácter colonial, llegando a constituir un verdadero país capitalista.

Durante 1932 Ortega traslada a la Revista la reflexión sobre la crisis económica, realizándose un esfuerzo por aportar soluciones europeas. El economista austriaco Ludwin von Misses, en Las causas de la crisis económica ${ }^{47}$, defendió un liberalismo económico puro, mediante el funcionamiento libre del mercado sin intervenciones públicas. Punto de vista que no compartió E. Lederer en Salida de la crisis económica ${ }^{48}$ donde apuntaba tímidamente la necesidad de una planificación. Ésta aparece formulada en El porvenir del capitalismo ${ }^{49}$, del alemán Werner Sombart quien defiende un plan con las características de totalidad, unidad y variedad; Sombart agregó un nuevo debate: economía mundial o autarquía nacional, por la que se decanta. La revista, finalmente, recupera el discurso liberal y librecambista con El destino del capitalismo alemán ${ }^{50}$, de M.J. Bonn, donde afirma que la política irracional de postguerra ha destruido al

45 LÜTKENS, Charlotte, "El Capitalismo norteamericano", RO, n. 9 95, mayo 1931, págs. 177-192

46 BonN, M.J., «El sentido de la crisis norteamericana", RO, n. 100, octubre 1931, págs. $105-117$

47 MISES, Ludwig, "Las causas de la crisis económica", RO, n. "104, febrero 1932, págs. 209-240.

48 LeDerer, E., "Salida de la crisis económica", $R O, n \cdot 108$, junio 1932, págs. 535-567, y "Salida de la crisis económica (conclusión) ", RO, n." 109, julio 1932, págs. 70-100

49 SOMBART, Werner, «El provenir del capitalismo", RO, n." 110, agosto de 1932, págs. 129-165.

50 BonN, M.J., “El destino del capitalismo alemán", RO, n. 112, octubre 1932, págs. 69-109. 
capitalismo como sistema económico racional, patente en el nacionalismo y en la política proteccionista.

En 1933 la revista presenta a Howard Scott como "adalid del movimiento norteamericano llamado "tecnocracia"»; Scott desarrolla un largo trabajo titulado Indagación sobre la naturaleza de la crisis actual ${ }^{51}$, en donde concluirá que «nuestro viejo sistema ha caducado y la nación tiene que digerir el hecho de que el sistema de precios se ha agotado por completo». Un año más tarde, la revista volvió a tratar la coyuntura económica. Un estudio titulado La Revolución Roosevelt ${ }^{52}$, de Luis Olariaga, dio cuenta de las reformas llevadas a cabo por el Presidente norteamericano Roosevelt, y que tendría continuidad en una Nota ${ }^{53}$, suscrita por Díaz del Moral en la que se comenta el libro de Molodovsky La lucha contra la crisis agraria en los Estados Unidos.

La publicación se desplaza a zonas más abstractas. Fernando Vela en Mundo limitado ${ }^{54}$ sostiene que las crisis obedecen justamente a que los principios vigentes en su momento para un mundo económicamente ilimitado devienen inoperantes cuando ese mundo se contrae. Para Fernando Vela el rnundo ampliado en 1492 quedó saturado en 1918. Fernando Vela se apoyan en el libro Renovation du capitalisme, de Pierre Lucius, y en la idea de finitud que Ortega y Gasset expresó en 1923 en un Apéndice a El tema de nuestro tiempo, y que llevó por título El sentido histórico de la teoría de la relatividad ${ }^{55}$. Vela concluirá que "en un mundo económico y político limitado tampoco puede existir nada con tendencia al infinito".

La perspectiva histórico-filosófica abierta por Fernando Vela tendrá continuidad en Economía y vida ${ }^{56}$, ensayo publicado en 1935 por Francisco Rivera Pastor. La lectura de la economía efectuada por Rivera Pastor enlaza con el vitalismo y la antropología de Ortega partiendo de la denuncia que el filósofo hizo sobre la crisis de la fundamentación de las ciencias físicas. La base de la Economía clásica sobre la Física moderna había quebrado, a juicio de Rivera Pastor. El móvil de la actividad económica no es el interés ni el egoísmo, sino la angustia vitae; ésta mueve al hombre a buscarse

\footnotetext{
51 Scott, Howard, "Indagaciones sobre la naturaleza de la crisis actual», $R O, n . " 119$, mayo 1933, págs. 147-181

52 Olariaga, Luis, "La Revolución de Roosevelt», RO, n."134, agosto 1934, págs. 162-189.

53 DIAZ DEL MORAL, J., «Nicolás Molodovsky: La lutte contre la crise agraire aux Etats- Unis.Libraire Techique et Economique. París.", RO, n. 152, febrero 1936, págs. 227-231.

54 VELA, Fernando, "Mundo limitado", RO, n." 131, mayo de 1934, págs. 123-153.

55 ORTEga y Gasset, O.C., Tomo III, 231-242.

56 RIVERa PASTOR, Francisco, «Economia y vida”, $R O$, n. 147 , septiembre 1935, págs. 349-362; y «Economia y vida (conclusión)», RO, n. 148, págs. 75-92.
} 
una base de sustentación en medio de las fuerzas hostiles que le rodean (corriente externa de la vida en que consiste la economía) y a preguntarse por el motivo de su existencia (corriente interna en que consiste la cultura).

\section{Y LA CRISIS DE LOS TREINTA}

La década de los treinta se inauguró con la Segunda República española que, en opinión de Ortega, presentaba una ocasión única para ensayar el ejercicio político de los intelectuales en la construcción de un Estado ejemplar para un mundo en crisis. Por ello, junto a Pérez de Ayala y Gregorio Marañón fundó la Agrupación al Servicio de la República. Elegido parlamentario, participó en la elaboración de la Constitución de 1931 y en la discusión de Estatuto Catalán. Pero, a juicio del pensador, la radicalización del régimen se oponía a su propuesta de cambio ordenado y jerarquizado.

Abandonada la actividad política republicana, de la que salió con un célebre "No es eso, no es eso", en el marco de una sociedad europea inmersa en la mayor recesión económica jamás conocida, todo aquel ambiente de crisis generalizada provocó en Ortega una reflexión filosófica para interpretar aquellos convulsos años. En 1933 Ortega pronuncia un curso bajo el título En torno a Galileo ${ }^{57}$, con ocasión del tercer centenario de la condena del Tribunal de la Inquisición en Roma aplicada al pensador italiano. Para Ortega, la faena del ser humano más radical es vivir, esto es, hacer algo, y esto requiere la libertad de tener que decidir qué es lo que va a hacerse en cada momento dentro de las posibilidades que la vida ofrece. Vivir es interpretar la vida de acuerdo a determinadas convicciones últimas (ideología) y tener conciencia de que el hombre se encuentra en una circunstancia con más o menos técnica o dominio sobre el contorno material (técnica). El historiador debe abandonar el psicologismo o subjetivismo y afrontar el problema de la estructura de la vida, de sus convicciones objetivas. Ese repertorio de convicciones es la cultura, lo que le da seguridad al hombre y le socializa.

Esa estructura de la vida y sus vigencias cambian, en opinión de Ortega, y ese cambio significa crísis. Las crisis surgen cuando las convicciones últimas sufren la negación de las generaciones nuevas y de repente el mundo se encuentra con que no rige ningún valor. Surge después un mundo nuevo en el momento en que comienza a afirmarse y tener vigor un nuevo sistema de convicciones a las que el hombre puede recurrir. La

$57 \quad \mathrm{~V}, 9-164$ 
crisis del mundo antiguo, la época del Renacimiento y el Occidente del siglo $x x$ son los ejemplos más claros de crisis y cambio en el mundo. Ortega no utiliza el término decadencia tan en boga durante los años veinte. En el año 1933 opta por los conceptos de cambio y crisis.

En 1934 publica la cuarta edición de España Invertebrada y escribe un Prólogo ${ }^{58}$ en el que la crisis europea deja su impronta. Según Ortega, muchas de las advertencias vertidas al inicio de los años veinte, se cumplían en todo el continente, en esencia, "el fracaso de las masas en su pretensión de dirigir la vida europea». Son los años de «la angustia, el dolor, el hambre y la sensación de vital vacío".

"Y entonces se verá, con gran sorpresa, que la exaltación de las masas nacionales y de las masas obreras, llevadas al paroxismo en los últimos treinta años, era la vuelta que ineludiblemente tenía que tomar la realidad histórica para hacer posible el auténtico futuro, que es, en una u otra forma, la unidad de Europa" ${ }^{59}$.

La influencia de Ortega en los colaboradores de la revista se acentúa. En la Nota al libro de Karl Jaspers, Ambiente espiritual de nuestro tiempo ${ }^{60}$, Maravall inicia su comentario recordando que la angustia vital del europeo, a pesar del progreso técnico, lo había tratado Ortega en El tema de nuestro tiempo y en la Rebelión de las Masas, sobre la base del ufracaso de la cultura hierático racionalista". Jaspers señala dos causas de la crisis: las "desdivinización" del mundo y el principio de la "tecnificación»; ambas tienen idéntico significado, a saber, el régimen existencial de las masas que anula las cualidades de lo personal. A pesar de ello, el Estado se presenta como un lugar de «posibilitación» del ser humano.

A la idea europea, Maravall aportó una reflexión histórica en Carlos $V$ y la unidad de Europa ${ }^{61}$, publicado en mayo de 1934. Aunque "la idea de una unidad europea existía en el pensamiento de Carlos V", afirma Maravall, lo cierto es que el emperador fracasó tanto en su política continental como en el gobierno de España.

En aquel ambiente hubo de parecerle oportuno a Ortega la publicación de un artículo de Ángel Sánchez Rivero, Las nacionalidades ${ }^{62}$, que aún

$58 \quad$ III, $43-45$.

$59 \quad 111,44$.

6o Mafavall, José Antonio, «Karl Jaspers: Ambiente espiritual de nuestro tiempo», RO, n. 125, noviembre 1933, págs. 215-220.

61 Maravall, José Antonio, "Carlos V y la Linidad de Europa", R.O., n. 131, mayo 1934, págs. 221-118

62 Sanchez Rivero, Angei, "Las riacionalidades", RO, n." 133, julio 1934, págs. 78-92. 
aparecido en el número de julio de 1934, databa de 1929. De acuerdo con una nota, el ensayo formaba parte del libro Meditaciones políticas editado por la Pen Colección. La crisis española puede explicarse por una crisis de la conciencia nacional. Según Sánchez Rivero «la destrucción de las clases superiores produjo la ruina de toda posibilidad nacional española (...) porque una gran nación es esencialmente obra de las clases superiores".

La revista desarrolló algún aspecto tratado en la Rebelión de las masas; así La población en el mundo ${ }^{63}$, un largo y documentado estudio de José Tudela en el número de mayo de 1935 . El autor sostiene que la demografía viene a esclarecer una gran serie de fenómenos históricos como en economia efectúo Werner Sombart o en política hizo Ortega y Gasset. El artículo repasa los datos aparecidos en La population dans le monde, de Gastón Bouthoul.

El sociólogo Karl Mennheim publicó aquel año Hombre y sociedad en época de transformación, que Fernando Vela se ocupó de comentar en Sociologia de una crisis ${ }^{64}$. El artículo repasaba cuestiones relativas a los elementos racionales e irracionales de en la sociedad, la democratización e interdependencia, la moralidad sustancial y funcional, la crisis de la cultura, la formación de la elite, su inserción y posición en la sociedad. Fernando Vela advertía al inicio de su comentario que la explicación dada por Mennheim era incompleta sino se atendía a la irrupción de las masas en la vida social y pública.

Un muy sensibilizado Maravall interviene nuevamente en la revista. Así en Europa en crisis ${ }^{65}$, una Nota al libro La crise de l'Europe, de André Siegfried, publicada en septiembre de 1935. Siegfried realiza, a juicio de Maravall, un estudio superficial de la crisis europea al centrarlo en exclusiva sobre aspectos políticos y económicos, cuyo debilitamiento ha originado el derrumbe de la hegemonía europea y la rebelión de Estados Unidos. Maravall afirma, en tono marcadamente orteguiano, que se ha producido una rebelión de las masas en el orden internacional de los pueblos extraeuropeos contra el viejo continente: «las masas americanas, asiáticas, australianas, se apoderan de los instrumentos de las elites europeas". La causa principal de tal situación radica en que Europa no detenta la capacidad de crear una cultura, de la que deriva todo, incluido, la preeminencia económica.

\footnotetext{
63 TUDELA, José, "La población en el mundo", RO, n. ${ }^{\circ}$ 143, mayo 1935, págs. 190-217.

64 VELA, Fernando, Sociologia de una crisis", $R O, n .{ }^{\circ} 146$, agosto 1935, págs. 129-160.

65 Maravall, José Antonio, “Europa en crisis», RO, n. 147, septiembre 1935, págs. 370-375.
} 
En diciembre de 1935 Miguel Prawdin publica La idea de Europa ${ }^{66}$. La crisis la cifra Prawdin en que durante el siglo XIX Europa hubo de adaptarse a la competencia material americana, con lo cual "no tenemos ya ninguna idea europea". Faltan los dos supuestos para que hubiera una idea europea: los hombres y la idea de comunidad humana. La técnica ha creado especialistas y estos han matado al hombre. No existe tampoco una comunidad en la que destaquen hombres espiritual y culturalmente creadores y que, a la vez, eleven el nivel medio de la masa. Prawdin maneja un concepto orteguiano, tributario de España Invertebrada: el particularismo; efectivamente, existe un "particularismo» europeo: las naciones no sólo se oponen política y territorialmente, sino que, además, se escinden internamente, lo que agrava aún más la ausencia de una comunidad europea. La idea de Europa planea las mentes de los hombres creadores, y sólo en la «comunidad de trato y cambio espiritual está el futuro de Europa».

\section{CONCLUSIONES}

Una de las grandes preocupaciones de Ortega fue la cuestión de la crisis de la conciencia europea. Había heredado de la generación del 98 , la del Desastre, !a cuestión sobre la identidad nacional de España y su proceso de decadencia como potencia internacional. La trasladó a la generación del 14, que Ortega lidera desde sus comienzos; la traumática experiencia de la Gran Guerra Europea apercibió al pensador del cambio mundial que se estaba operando en todos los ordenes. España debía regenerarse aprovechando su neutralidad al conflicto.

Sin embargo, la crisis española de 1917 a 1921 y la difícil postguerra europea provocaron en el pensador una doble sentencia: España estaba invertebrada y Europa se hallaba en una depresión espiritual cuyas profundas raíces precedian a la conflagración. Únicamente, la acción cultural de las minorias egregias podía articular a una inerte nación española y recuperar al viejo continente.

En 1923 nadie como el pensador español se encontraba, por tanto, en disposición de afrontar el temá de la crisis e impulsó decididamente su estudio mediante la fundación de la Revista de Occidente. Frente al fracaso del internacionalismo político representado por la Sociedad de Naciones opuso el cosmopolitismo de la inteligencia; la publicación se erigió

66 Pradwin, Miguel, “La idea de Europa”, RO, n. 150, diciembre 1935, págs. 267-273. 
en el foro de encuentro y debate de un importante grupo de intelectuales europeos y americanos, aplicados con esmero a pulsar y diagnosticar qué le ocurría a Europa.

Hasta 1930, los colaboradores abordan la decadencia y unidad de Europa, sus cambios culturales, y el papel a desempeñar por los intelectuales en aquel proceso. La revista prestó atención al comunismo y al fascismo, esencialmente a través del impacto recibido por la inteligencia europea. Era común la opinión de la revista de que los intelectuales, en línea muy orteguiana, debían alejarse de todo compromiso político y recogerse en la elaboración de una nueva cultura, entendida ésta como un sistema de valores en todos los órdenes.

La publicación de los artículos que después conformaron la Rebelión de las masas, coincide temporalmente con el Crack del 29. A partir de entonces la revista incorporó el esquema explicativo de la obra de Ortega como si de un axioma se tratara, evidente, por ejemplo, en Vela y Maravall: las crisis de Occidente, política o social, incluida la gran depresión económica, no podía ignorar le hecho del fracaso de las masas en dirigir la vida europea.

La Revista de Occidente no fue, obviamente, una publicación económica, pero sin duda interesó de los colaboradores su opinión sobre la Depresión que asoló la economía mundial de los años treinta. En el debate suscitado desde sus páginas confluyen las posiciones liberales y socialdemócratas, los partidarios y opositores a la planificación, quienes propugnaban la autarquía frente a los defensores de una economía mundial. Por países, Estados Unidos y Alemania centraron casi en exclusiva la atención de los economistas. Fernando Vela y Rivera Pastor explicaron los fenómenos económicos sobre la base de la filosofía de Ortega y Gasset.

Durante los años treinta la revista alteró su jerga: abandona la palabra decadencia y utiliza el concepto crisis. A ello contribuyó la toma de conciencia por parte de los colaboradores de encontrase no tanto ante una decadencia de Europa, que necesitaba el referente externo de unos Estados Unidos cuya prosperity se desplomó cual castillo de naipes, cuanto ante el indiscutible hecho del cambio de valores, interno a la propia sociedad europea.

En definitiva, Europa en la conciencia de los intelectuales, colaboradores de la Revista de Occidente, estuvo inmersa en una profunda crisis cuyas causas comunes a todos ellos eran el materialismo, la técnica y el maquinismo, y el advenimiento de las masas al poder social. El porvenir de Europa pasa por su unidad con el objeto de recuperar el liderato cultural y espiritual en el mundo. 


\section{FUENTES Y BIBLIOGRAFIA}

\section{Fuentes Hemerográficas}

Revista de Occidente (Madrid, julio 1923-julio 1936).

\section{Obras de José Ortega y Gasset}

Ortega y Gasset, José (1974): Discursos políticos, Edición de Paulino Garagorri. Madrid, Alianza Editorial.

- (1981): España Invertebrada, Edición de Paulino Garagorri. Madrid, Revista de Occidente, 2. ${ }^{\text {E Edición }}$

- (1991): Cartas de un joven español, Edición de Soledad Ortega. Madrid, Ediciones El Arquero.

- (1994): Obras Completas. Madrid, Alianza Editorial (1. ${ }^{a}$ edición en Alianza Editorial, 2. ${ }^{a}$ reimpresión), 12 vols.

- (1996): Meditación de nuestro tiempo. Las conferencias de Buenos Aires, 1916 y 1928 , Edición de José Luis Molinuevo. Madrid, Fondo de Cultura Europea.

- (1998): La rebelión de las masas, Edición de Thomas Mermall. Madrid, Editorial Castalia.

- (1998): Europa y la idea de nación, Edición de Paulino Garagorri. Madrid, Alianza Editorial.

\section{Bibliografía sobre Ortega y Gasset}

AbelLÁN, Jnsé Luis (2000): Ortega y Gasset y los origenes de la transición democrática. Madrid, Espasa-Caipe.

- "Ortega y Gasset: los malentendidos sobre su figura". El País, 9 de junio de 2000.

CACHo VIu, Vicente (2000): Los intelectuales y la política. Perfil público de Ortega y Gasset. Madrid, Biblioteca Nueva.

CEPEdA CAlzAdA, Pablo (1968): Las ideas políticas de Ortega y Gasset. Valladolid, Universidad de Valladolid.

Elorza, Antonio (1984): La razón y la sombra. Una Lectura polííica de Ortega y Gasset. Barcelona, Editorial Anagrama.

Gray, RockWELL, (1994): José Ortega y Gasset. El imperativo de la modernidad. Una biografía humana e intelectual. Madrid, Espasa Calpe.

LóPEZ Frias, Francisco (1985): Ética y política. En torno al pensamiento político de J. Ortega y Gasset. Barcelona, Promociones Publicaciones Universitarias.

MARIAS, Julián (1983): Ortega I. Circunstancia y vocación. Madrid, Alianza.

Martin Luengo, Mercedes (1999): José Ortega y Gasset. Madrid, Rueda.

ORTEGa, Miguel (1983): Ortega y Gasset, mi padre. Barcelona, Editcrial Planeta.

REDONDO, Gunzalo (1974): Las empresas politicas de José Ortega y Gasset, 2 vols. Madrid, Editorial Rialp.

TEJADA, Ricardo (1999): «Lo nacional y lo liberal en el pensamiento político de Ortega y Gasset». Cuadernos de Alzate, 13-49.

VARGAS Llosa, Mario «El filósofo enı la sacristía», El País, 1 de marzo de 1998.

\section{Bibliografía consultada}

Abellan, José Luis (1978): Panorama de la Filosotia española actual. Madrid, Espasa-Calpe. AbELLAN-Garcia, José Luis (1991): Historia crítica del pensamiento español. Madrid, EspasaCalpe, 8 vols. 
ARENDT, Hannah (1974): Los origenes del totalitarismo. Madrid, Taurus.

BÉCARUD, J. y Lópz CAMPILlo, E. (1978): Los intelectuales españoles durante la II República. Madrid, Siglo $x \times 1$ de España Editores, SA.

BELTRAN, Lucas (1970): Historia de las doctrinas económicas. Barcelona, Teide.

BENEYTo, José María (1999): Tragedia y Razón. Europa en el pensamiento de español del siglo xx. Madrid, Santillana.

Fusı AIzPURúA, Juan Pablo "La crisis de la conciencia europea" en Historia 16, Historia Universal. Siglo $x x$, núm. 8 , págs. 101-118.

Garcia QuiePo DE Llano, Genoveva (1988): Los intelectuales y la dictadura de Primo de Rivera. Madrid, Alianza Editorial.

GAzIER, Bernard (1994): El Crac del 29. Madrid, Globus Comunicación.

JACKSON, Gabriel (1982): La República Española y la Guerra Civil. Barcelona, Critica.

- (1997): Civilización y Barbarie en la Europa del siglo xx. Barcelona, Planeta.

KENNEDY, Paul (1994): Auge y Caida de las grandes potencias. Barcelona, Plaza y Janés.

Lain Entralgo, Pedro (1956): La generación del noventa y ocho. Madrid, Espasa Calpe.

LÓPEZ-CAMPILLO, Evelyne (1972): "La Revista de Occidente" y la formación de minorias, 1923 1936. Madrid, Taurus Ediciones.

MAriAs, Julián (1956): Filosofía española actual. Unamuno, Ortega, Morente, Zubiri. Madrid, Espasa-Calpe (Colección Austral, n. ${ }^{\circ} 804$ ).

- (1996): España ante si y ante la Historia (1898-1936). Madrid, Espasa Calpe.

MeRLEAU-PONTY, Jacques (1993): Albert Einstein. Vida, obra y filosofía. Madrid, Alianza Editorial.

Neila Hernandez, José Luis (1997): La Sociedad de Naciones. Madrid, Arcos Libros.

Núñez Rivero, Cayetano y Martinez Segarra, Rosa María (1997): Historia constitucional de Es. paña. Madrid, Universitas.

Paris, Robert (1976): Los origenes del fascismo. Barcelona, Península.

Renouvin, Pierre (1994): La Primera Guerra Mundial. Madrid, Globus Comunicación.

- (1990): Historia de las relaciones internacionales. Madrid, Akal, 2 vols.

TANNEBBaum, Edward R. (1975): La experiencia fascista. Sociedad y cultura (1922-1945). Madrid, Alianza Editorial.

VAllespin, Fernando (1994): (edit.), Historia de la teoria politica. Madrid, Alianza Editorial, 6 vols. 